\title{
PENGARUH VEGETASI KAWASAN SABUK HIJAU (GREEN BELT) WADUK SERMO KULONPROGO TERHADAP KENAMPAKAN HASIL PROSES EROSI DAN PEMANFAATAN OLEH MASYARAKAT
}

\author{
Nanik Lisawati Dwi Rahayu ${ }^{1}$, Sudarmadji ${ }^{2}$ dan Lies Rahayu Wijayanti Faida ${ }^{3}$
}

Sekolah Pasca Sarjana Universitas Gadjah Mada ${ }^{1,2}$, Kehutanan Universitas Gadjah Mada, Yogyakarta ${ }^{3}$ nanik_lisawati@yahoo.co.id

Diterima : Juni 2015; Direvisi: November 2015.; Dipubikasikan: Maret 2016

\begin{abstract}
ABSTRAK Manfaat sabuk hijau Waduk Sermo dan pengelolaan yang baik dapat dipenuhi dengan terciptanya kondisi vegetasi dan sikap stakeholder yang mendukung keberadaan sabuk hijau. Penelitian ini bertujuan untuk mengetahui strata dan komposisi jenis vegetasi Kawasan Sabuk Hijau Waduk Sermo di Kulonprogo, menganalisis hubungannya dengan kenampakan hasil proses erosi serta menganalisis nilai pemanfaatan lahan sabuk hijau oleh masyarakat. Analisis vegetasi dilakukan pada 6 blok vegetasi yang dominan untuk mengetahui strata dan komposisi jenis vegetasi. Regresi logistik untuk menganalisis hubungan vegetasi dengan kenampakan hasil proses erosi antara variabel bebas (tinggi pohon, kerapatan tajuk pohon, LBDS (Luas Bidang Dasar) pohon, kerapatan pohon) dengan variabel tergantung nilai skoring erosi visual menurut Morgan (1980). Untuk menganalisis nilai pemanfaatan sabuk hijau dilakukan indepth interview terhadap stakeholder dan pengumpulan data menggunakan kuisioner terhadap petani penggarap sabuk hijau. Hasil penelitian menunjukkan kelapa dan sengon menjadi ciri khas vegetasi Kawasan Sabuk Hijau waduk Sermo. Terdapat 28 jenis vegetasi, 15 famili dalam strata pohon, tiang, sapihan, dan semai dengan indeks nilai keragaman $(\mathrm{H})$ tingkat sedang. Jenis pohon yang berbeda mempunyai daya cegah terhadap erosi yang berbeda yang dapat dilihat dari kenampakan hasil proses erosi dibawah tegakan tunggal. Regresi logistik menunjukkan hanya variabel LBDS yang mempengaruhi kejadian erosi. Nilai pemanfaatan langsung hasil Kawasan Sabuk Hijau Waduk Sermo menurut petani penggarap adalah besar sehingga keterlibatan pemanfaatan areal sabuk hijau sulit untuk dicegah.
\end{abstract}

Kata kunci: erosi; masyarakat; sabuk hijau; vegetasi hutan; Waduk Sermo.

ABSTRACT The advantage of Sermo reservoir green belt and good management can be gained, provided that the condition of vegetation and attitudes of stakeholders support the existence of the green belt. The study aimed to figure out the strata and composition of vegetation in Sermo reservoir green belt in Kulonprogo, how they are related to occuring erosion features, and the value of the green belt utilization by the community.Vegetation analysis was performed on six dominant vegetational blocks to find out the strata and composition of vegetation. Logistic regression was performed to find out the relation between vegetation and erosion features, between independent variables (tree height, canopy density, tree basal area (BA), tree density) and dependent variables of visual erosion scoring according to Morgan (1980). The value of green belt utilization was determined using in-depth interviews with stakeholders and data gathering using questionnaires to farmers cultivating the green belt.The findings suggest that coconut and sengon are the characteristic vegetations in Sermo reservoir green belt. There are 28 types of vegetation and 15 families in tree, pole, sapling, seedling strata with moderate value of heterogeneity index. Different types of tree have different erosion prevention capabilities, observed from erosion features under single stands. Logistic regression suggested that only BA variables influence erosion occurence. The value of direct utilization of Sermo reservoir green belt reaching is a large amount according to the farmers so that involvement in utilizing the green belt area can be difficult to avoid.

Keywords: erosion; community; green belt; forest vegetation; Sermo Reservoir.

\section{PENDAHULUAN}

Waduk Sermo merupakan satu-satunya waduk di Propinsi Daerah Istimewa Yogyakarta yang dibangun pemerintah pada tahun 1997 dengan luas kurang lebih 157 ha, terletak di Desa Hargowilis, Kecamatan Kokap, Kabupaten Kulonprogo. Pembangunan Waduk Sermo bertujuan untuk pemasok air irigasi Sistem Kalibawang dengan areal 7.152 ha yang merupakan interkoneksi dari beberapa daerah irigasi, sebagai penanggulangan bencana banjir Kota Pengasih dan Wates, penyedia bahan baku air minum PDAM, dan kegiatan pariwisata.

Kawasan Sabuk Hijau (green belt) Waduk Sermo yang berada di sekeliling waduk dibuat untuk 
mencegah erosi pada lereng (sempadan) waduk, menjaga stabilitas tanah dan sebagai kawasan yang memisahkan waduk dengan lahan disekelilingnya. Biaya pembangunan waduk memerlukan investasi yang besar sehingga diharapkan umur pakai waduk dapat sesuai rencana atau bahkan lebih lama dengan cara memelihara fungsi sabuk hijau dengan baik.

Pohon sebagai penyusun sabuk hijau berfungsi untuk menghalangi jatuhnya air hujan sehingga mengurangi erosi percik, menghambat aliran permukaan, memperbanyak air infiltrasi, dan mencegah evaporasi berlebih. Kemampuan vegetasi untuk menahan erosi dipengaruhi oleh semua komponen pohon dari daun sampai akar secara individu dan bersama-sama dalam suatu kelompok vegetasi di suatu kawasan hutan. Tipologi tanaman yang mempunyai tajuk rapat mampu menurunkan energi kinetik hujan sehingga mampu menekan kehilangan tanah akibat erosi. Semakin lengkap strata dan jenis vegetasi makin besar kemampuannya menahan erosi (Widjajani, 2010).

Pengaruh jenis tanaman terhadap aliran permukaan dipengaruhi beberapa faktor antara lain tingkat pertumbuhan tanaman, ketinggian tanaman, keadaan daun tanaman, kerapatan tanaman dan sistem perakaran (Wudianto, 2000 dalam Ziliwu, 2002). Akar tumbuh-tumbuhan mampu mengikat dan mencengkeram tanah sehingga memperkuat stabilitas lereng. Ketebalan massa daun yang jatuh akan menghalangi aliran permukaan dan memecah diameter butir hujan (Dibyosaputro dkk., 2009).

Riwayat historis Kawasan Sabuk Hijau (green belt) Waduk Sermo berasal dari pembebasan lahan pribadi penduduk Hargowilis menyebabkan sebagian masyarakat merasa ikut memiliki dan mengolah kawasan sabuk hijau untuk kegiatan pertanian dan memenuhi kebutuhan makanan ternak. Aktivitas petani dalam memanfaatkan dan mengelola kawasan sabuk hijau tersebut dikhawatirkan akan memberikan dampak negatif dari fungsi ekologisnya sebagai pelindung dari erosi sempadan waduk.

Penelitian ini dilakukan untuk melihat kondisi vegetasi di Kawasan Sabuk Hijau (green belt) Waduk Sermo dan menganalisis hubungannya dengan kenampakan hasil proses erosi yang merupakan indikator terjadinya erosi seperti tanah gundul, pedestal, kenampakan akar, bekas aliran permukaan, erosi alur dan parit (USDA, 2001). Keterlibatan masyarakat dalam memanfatkan sabuk hijau juga di analisis sehingga nilai sabuk hijau bagi masyarakat dan pihak terkait dapat diketahui sehingga faktor-faktor yang bertentangan dengan fungsi lindung dapat dicarikan solusinya.

\section{METODE PENELITIAN}

Lokasi penelitian berada di Kawasan Sabuk Hijau Waduk Sermo seluas 50 ha. Penentuan blok sampel didasarkan pada pendekatan observasi lapangan lengkap dengan pengamatan menggunakan perahu mengelilingi sabuk hijau pada area waduk dan kendaraan dari area darat. Berdasarkan ciri fisiognomi vegetasi didapatkan 6 jenis vegetasi dominan yang kemudian disebut sebagai blok vegetasi yaitu: Blok I. Kelapa; Blok II. Akasia; Blok III. Jati; Blok IV. BuahBuahan; Blok V. Sengon dan Blok. VI Tegal Campuran ditunjukkan pada Gambar 1.

Penempatan plot pada masing-masing blok vegetasi dengan metode jalur berpetak dengan arah tegak lurus jalan lingkar waduk (memotong lereng). Setiap jalur dibuat 2 plot masing-masing dengan ukuran $20 \mathrm{~m}$ x 20 $m$ dengan 3 kali ulangan sehingga masing-masing blok akan didapatkan 6 plot. Ukuran plot untuk pohon adalah $20 \mathrm{~m}$ x $20 \mathrm{~m}$; tiang adalah: $10 \mathrm{~m}$ x $10 \mathrm{~m}$; sapihan $5 \mathrm{~m}$ x $5 \mathrm{~m}$; semai $2 \mathrm{~m} \times 2 \mathrm{~m}$.

Data vegetasi diamati pada setiap plot adalah jumlah individu, jenis, tinggi, diameter batang setinggi dada $(1.3 \mathrm{~m})$ pada strata pohon, tiang, sapihan dan semai. Analisis vegetasi yang dilakukan meliputi Kerapatan Jenis, Kerapatan Relatif, Dominansi Jenis, Dominansi Relatif, Frekuensi Jenis, frekuensi Relatif, Indeks Nilai Penting (INP) dan Indeks Keragaman (H) (Barbour dkk., 1987).

Pengambilan gambar kerapatan tajuk dilakukan dengan kamera tegak keatas sebanyak 3 tempat pada jarak yang sama dalam salah satu garis diagonal petak ukur. Nilai kerapatan tajuk dicocokkan dengan standar USDA FIA Canopy Cover Estimatimation Chart untuk mengetahui prosentase kerapatannya (Korhonen dkk., 2006).

$\mathrm{pH}$ tanah dicatat setiap blok dengan cara pengambilan data secara random sebanyak 3 kali. Sampel tanah diambil dari masing-masing blok (6 sampel) dengan mengebor tanah sampai kedalaman 30 $\mathrm{cm}$ masing-masing blok pada 3 titik secara random dikomposit diambil sebanyak $1 \mathrm{~kg}$. Sampel tanah kemudian dibedakan menjadi 2 unit analisis yaitu analisis I meliputi komposit tanah Blok I, Blok II, Blok III dan analisis II meliputi komposit tanah Blok IV, Blok V dan Blok VI (Gambar 1). Sampel tanah tersebut kemudian dianalisis di laboratorium Tanah Balai Penelitian Tanah (BPT) Yogyakarta meliputi tekstur, kandungan unsur $\mathrm{N}$ total (metode Kyeldahl), $\mathrm{P}$ tersedia 
(metode Olsen), $\mathrm{K}$ tersedia, dan $\mathrm{C}$ organik (Walkey and Black).

Data erosi didapatkan dari pengamatan tandatanda erosi visual dicatat nomor plotnya, diambil gambarnya dicocokkan dengan skoring nilai kenampakan hasil proses erosi ditunjukkan pada Tabel 1.

Hubungan antara vegetasi dengan kenampakan hasil proses erosi dilakukan analisis regresi logistik (Hosmer dan Lemeshow, 2013). Variabel bebas meliputi tinggi pohon, kerapatan tajuk pohon, Luas Bidang Dasar pohon (LBDS), kerapatan pohon. Nilai skoring erosi visual menurut Morgan (1980) sebagai variabel tergantung.

Untuk mengetahui nilai pemanfaatan sabuk hijau dan sikap masyarakat terhadap keberadaan sabuk hijau dilakukan indept interview terhadap stake holder dan pengumpulan data menggunakan kuisioner terhadap petani penggarap sabuk hijau sebanyak 20\% (Arikunto, 1998). Data yang didapatkan dari jawaban indept interview dianalisis deskriptif dengan mengelompokkan informasi yang sama sehingga dapat memberikan jawaban tujuan penelitian. Data dari hasil jawaban kuisioner petani penggarap sabuk hijau dianalisis menggunakan Skala Likert (Azwar, 2013).

\section{HASIL DAN PEMBAHASAN}

Kondisi lereng yang curam sampai sangat curam di Kawasan Sabuk Hijau Waduk Sermo, jenis tanah Latosol (agak peka) dan Litosol (sangat peka) terhadap erosi, serta curah hujan tahunan pada beberapa tahun terakhir diatas $2000 \mathrm{~mm} / \mathrm{th}$ berpotensi menyebabkan erosi cukup tinggi. Tekstur tanah geluh lempung kepasiran berpengaruh pada kemudahan meloloskan air dan udara sehingga mempermudah air infiltrasi (Hardjowigeno, 1989). Hasil analisis tanah Kawasan Sabuk Hijau Waduk Sermo ditunjukkan pada Tabel 2.

pH Kawasan Sabuk Hijau Waduk Sermo cukup netral yaitu antara 5,9-6,4. Kondisi ini baik karena unsur hara mudah diserap akar tanaman pada $\mathrm{pH}$ netral dengan mudah larut dalam air. Bakteri pengikat nitrogen dari udara dan bakteri nitrifikasi juga dapat berkembang dengan baik pada $\mathrm{pH}$ lebih dari 5.5. Berdasarkan kriteria penilaian hasil analisis Tanah BPT (2009) nilai N tanah Kawasan Sabuk Hijau Waduk Sermo sangat rendah. Nilai $\mathrm{N}$ yang sangat rendah dapat disebabkan oleh rendahnya dekomposisi bahan organik dan kemiringan tanah yang tajam di areal sabuk hijau sehingga terjadi aliran permukaan dimana pada permukaan tanah biasanya mengandung $\mathrm{N}$ tertinggi. Unsur $\mathrm{C}, \mathrm{P}$, dan $\mathrm{K}$ dalam kriteria rendah sehingga perlu penambahan unsur hara tersebut dengan pupuk tambahan untuk keperluan masa pertumbuhan tanaman dengan baik. Analisis vegetasi berkayu pada 6 blok penelitian dengan luas 1,36 ha terdapat 28 jenis vegetasi yang termasuk dalam 15 famili, terdiri atas 217 individu pohon, 42 tiang, 78 sapihan, dan 28 semai. Jenis vegetasi yang ada dalam 1 blok hanya terdapat kurang dari 9 jenis saja, hal ini ditunjukkan dengan nilai keragaman rendah sampai sedang (H 1-3 keragaman sedang) pada setiap blok seperti pada Tabel 3.

Jumlah individu strata pohon mendominasi semua blok diikuti sapihan dan tiang. Strata semai tidak terdapat pada Blok I dan Blok V hal ini menunjukkan permudaan alami sulit terjadi dengan dugaan adanya intervensi manusia untuk pembersihan lahan guna pemanfaatan lahan karena dari kualitas tanah dan iklim terdapat kesesuaian syarat tumbuh.

Jenis vegetasi yang ada berupa tanaman kayu, MPTS (Multi Purpose Tree Species) yaitu tanaman berkayu yang dapat menghasilkan buah atau daun yang bermanfaat dan HMT (Hijauan Makanan Ternak) dapat dilihat pada Tabel 4.

Kehadiran jenis tiap blok dapat dilihat dari Indek Nilai Penting (INP) yang merupakan penjumlahan dari Kerapatan Relatif (KR), Frekuensi Relatif (FR) dan Dominansi Relatif (DR). Nilai INP yang semakin besar menunjukkan peranan keberadaan suatu jenis dalam komunitas. Pada Gambar 2 ditampilkan 3 INP tertinggi masing-masing blok penelitian menunjukkan kelapa hadir dalam kelima blok dan sengon hadir dalam ketiga blok. Hal ini menunjukkan kedua jenis vegetasi ini menjadi ciri khas vegetasi Kawasan Sabuk Hijau Waduk Sermo. Nilai INP tertinggi pada masingmasing blok dengan besarnya INP jenis kedua terlihat begitu nyata kecuali pada Blok IV yang menunjukkan INP durian sebesar 74,09 \% dan INP kelapa sebesar $73,82 \%$.

Nilai Kerapatan Relatif (KR) tertinggi adalah pohon sengon Blok V (75\%) disusul kelapa Blok I (73,58\%). Nilai kerapatan merupakan gambaran jumlah spesies pada lokasi penelitian tetapi belum bisa menggambarkan distribusi dari frekuensi. Nilai Frekuensi Relatif jenis yang lebih tinggi dari masingmasing blok menunjukkan distribusi pohon lebih menyebar dibanding dengan nilai yang lebih rendah. Nilai kerapatan yang tinggi pada tegakan yang banyak terjadi permudaan alami menggambarkan bahwa jenis tersebut merupakan jenis pemenang dalam persaingan dan mempunyai toleransi yang lebar sehingga per 
satuan luas terdapat jumlah individu yang lebih besar.

Kerapatan pohon yang ada sebanyak 217/1,36 ha atau 160/ha dengan Kerapatan Relatif Jenis tertinggi sengon pada Blok V 50\%. Kerapatan pohon secara keseluruhan masih jarang sehingga masih diperlukan penanaman bibit sejenis dan pengkayaan jenis vegetasi baru.

Tabel 1. Skoring Nilai Kenampakan Hasil Proses Erosi

\begin{tabular}{|c|c|}
\hline Kode & Indikator \\
\hline 0 & $\begin{array}{l}\text { Tidak ada akar pohon yang terlihat di atas permukaan tanah, tidak ada pengerasan kulit permukaan, tidak ada pedestal, } \\
\text { tanaman penutup 70\% (lantai hutan dan kanopi). }\end{array}$ \\
\hline $1 / 2$ & $\begin{array}{l}\text { Sedikit dari akar pohon terlihat di permukaan tanah, sedikit pengerasan permukaan tanah, tidak ada pedestal, tingkat tanah } \\
\text { sedikit lebih tinggi pada sisi yang lebih tinggi atau bila terdapat batu, tanaman penutup } 30-70 \% \text {. }\end{array}$ \\
\hline 1 & $\begin{array}{l}\text { Paparan akar pohon, terlihat pedestal, gundukan tanah yang dilindungi oleh vegetasi 1-10 mm, sedikit pengerasan kulit } \\
\text { permukaan, tanaman penutup } \quad 30-70 \% \text {. }\end{array}$ \\
\hline 2 & $\begin{array}{l}\text { Paparan akar pohon, adanya pedestal, tanah gundukan sampai kedalaman } 1-5 \mathrm{~cm} \text {, pengerasan kulit permukaan, tanaman } \\
\text { penutup } 30-70 \% \text {. }\end{array}$ \\
\hline 3 & $\begin{array}{l}\text { Paparan akar pohon, pedestal dan gundukan tanah hingga kedalaman 5-10 cm, permukaan tanah berkurang } 2-5 \mathrm{~mm} \text {, } \\
\text { rumput berlumpur tanda tercuci hujan dan merunduk, tanaman penutup kurang dari } 30 \% \text {. }\end{array}$ \\
\hline 4 & $\begin{array}{l}\text { Paparan akar pohon, pedestal dan gundukan tanah hingga kedalaman 5-10 cm, material tanah kasar berserakan, parit yang } \\
\text { hingga } 8 \mathrm{~cm} \text { dalam, tanah kosong. }\end{array}$ \\
\hline 5 & Erosi parit, erosi alur lebih dari $8 \mathrm{~cm}$, tanah pasir tersingkap, tanah gundul \\
\hline
\end{tabular}

Sumber: Morgan (1980)

Tabel 2. Hasil Analisis Tanah Sabuk Hijau Waduk Sermo

\begin{tabular}{lcccccccc}
\multicolumn{1}{c}{ Sifat Tanah } & $\begin{array}{l}\text { Tekstur } \\
\text { Pasir } \\
(\%)\end{array}$ & $\begin{array}{l}\text { Debu } \\
(\%)\end{array}$ & $\begin{array}{l}\text { Liat } \\
(\%)\end{array}$ & pH & $\begin{array}{c}\text { C } \\
\text { organik }\end{array}$ & $\begin{array}{c}\text { N } \\
\text { Total }\end{array}$ & $\begin{array}{c}\text { P } \\
\text { Ppm } \\
\text { Olsen }\end{array}$ & $\begin{array}{c}\text { K } \\
\text { Tersedia } \\
(/ 100 \text { gr })\end{array}$ \\
\hline $\begin{array}{l}\text { Analisis I } \\
\text { Komposit tanah Blok I; Blok II, Blok III }\end{array}$ & 47 & 47 & 6 & $6,3-6,4$ & 1,14 & 0,09 & 7 & 0,17 \\
$\begin{array}{l}\text { Analisis II } \\
\text { Komposit tanah Blok IV; Blok V; Blok }\end{array}$ & 28 & 64 & 7 & $5,9-6,0$ & 0,59 & 0,07 & 8 & 0,21 \\
VI & & & & & & & & \\
\hline
\end{tabular}

Sumber: Data Primer (2014)

Tabel 3. Data Strata Vegetasi

\begin{tabular}{|c|c|c|c|c|c|c|c|c|c|c|c|c|c|}
\hline \multirow{2}{*}{\multicolumn{2}{|c|}{ Luas Blok (ha) }} & \multicolumn{4}{|c|}{$\sum$ Individu } & \multicolumn{4}{|c|}{$\Sigma$ Jenis } & \multicolumn{4}{|c|}{ H (Keragaman) } \\
\hline & & $\mathrm{P}$ & $\mathrm{T}$ & $\mathrm{Sp}$ & $\mathrm{S}$ & $\mathrm{P}$ & $\mathrm{T}$ & $\mathrm{Sp}$ & $\mathrm{S}$ & $\mathrm{P}$ & $\mathrm{T}$ & $\mathrm{Sp}$ & $\mathrm{S}$ \\
\hline Blok I & 0.24 & 53 & 1 & 8 & 0 & 7 & 1 & 4 & 0 & 0,97 & 0,32 & 1,21 & 0 \\
\hline Blok II & 0.24 & 44 & 6 & 5 & 5 & 6 & 3 & 2 & 3 & 1,3 & 0,87 & 0,45 & 0,95 \\
\hline Blok III & 0.24 & 22 & 4 & 6 & 3 & 4 & 2 & 2 & 3 & 1.10 & 0,56 & 0,45 & 1,1 \\
\hline Blok IV & 0.16 & 31 & 11 & 33 & 6 & 9 & 7 & 6 & 5 & 1,9 & 1,89 & 1,24 & 0,62 \\
\hline Blok V & 0.24 & 36 & 7 & 8 & 0 & 3 & 3 & 5 & 0 & 0,56 & 0,8 & 1,49 & 0 \\
\hline Blok VI & 0.24 & 31 & 13 & 18 & 14 & 5 & 5 & 8 & 7 & 1 & 1,38 & 1,94 & 1,77 \\
\hline Total & 1.36 & 217 & 42 & 78 & 28 & \multicolumn{4}{|c|}{$\Sigma$ Jenis/Blok $\leq 9$} & \multicolumn{4}{|c|}{ H/ blok $0,32-1,9$} \\
\hline
\end{tabular}

Keterangan : P=Pohon; $\mathrm{T}=$ Tiang; $\mathrm{Sp}=$ Sapihan; $\mathrm{S}=$ Semai

Sumber: Analisis Data Primer (2014)

Tabel 4. Jenis Vegetasi Kawasan Hutan Lindung Sabuk Hijau Waduk Sermo

\begin{tabular}{rllll}
\hline No. & Nama Lokal & Nama Botani & Famili & Kegunaan \\
\hline 1. & Akasia & Acacia mangium & Acaciaceae & Kayu \\
2. & Pulai & Alstonia scholaris & Apocynaceae & Kayu \\
3. & Kelapa & Cocos nucifera & Arecaceae & MPTS \\
4. & Mangga & Mangifera indica & Anacardiaceae & MPTS \\
5. & Kepel & Stelechocarpus burahol & Annonaceae & MPTS \\
6. & Ketapang & Terminalia cattapa & Combretaceae & MPTS \\
\hline
\end{tabular}




\begin{tabular}{|c|c|c|c|c|}
\hline 7. & Kiara payung & Filicium decipiens & Sapindaceae & Perindang \\
\hline 8. & Rambutan & Nephelium lappaceum & Sapindaceae & MPTS \\
\hline 9. & Singkong karet & Manihot glaziovii & Euphorbiaceae & MPTS \\
\hline 10. & Kemiri & Aleurites moluccana & Euphorbiaceae & MPTS \\
\hline 11. & Gamal & Gliricedia sepium & Fabaceae & HMT \\
\hline 12. & Munggur & Samanea saman & Fabaceae & Kayu \\
\hline 13. & Petai & Parkia speciosa & Fabaceae & MPTS \\
\hline 14. & Sengon & Albizia falcate & Fabaceae & Kayu \\
\hline 15. & Angsana & Pterocarpus indicus & Fabaceae & Kayu \\
\hline 16. & Lamtoro & Leucaena leucocephala & Fabaceae & HMT \\
\hline 17. & Cengkih & Zygium aromaticum & Myrtaceae & MPTS \\
\hline 18. & Kayu Putih & Melaleuca leucadendron & Myrtaceae & MPTS \\
\hline 19 & Melinjo & Gnetum gnemon & Gneataceae & MPTS \\
\hline 20. & Kapuk & Ceiba pentandra & Malvaceae & MPTS \\
\hline 21. & Kakao & Theobroma cacao & Malvaceae & MPTS \\
\hline 22. & Waru & Hibiscus tiliaceus & Malvaceae & MPTS \\
\hline 23. & Durian & Durio zibethinus & Malvaceae & MPTS \\
\hline 24. & Mahoni & Swietenia mahagoni & Meliaceae & Kayu \\
\hline 25. & Nangka & Artocarpus heterophyllus & Moraceae & MPTS \\
\hline 26. & Sukun & Artocarpus atilis & Moraceae & MPTS \\
\hline 27. & Melina & Gmelina arborea & Verbenaceae & Kayu \\
\hline 28. & Jati & Tectona grandis & Verbenaceae & Kayu \\
\hline
\end{tabular}

Sumber: Data Primer (2014)

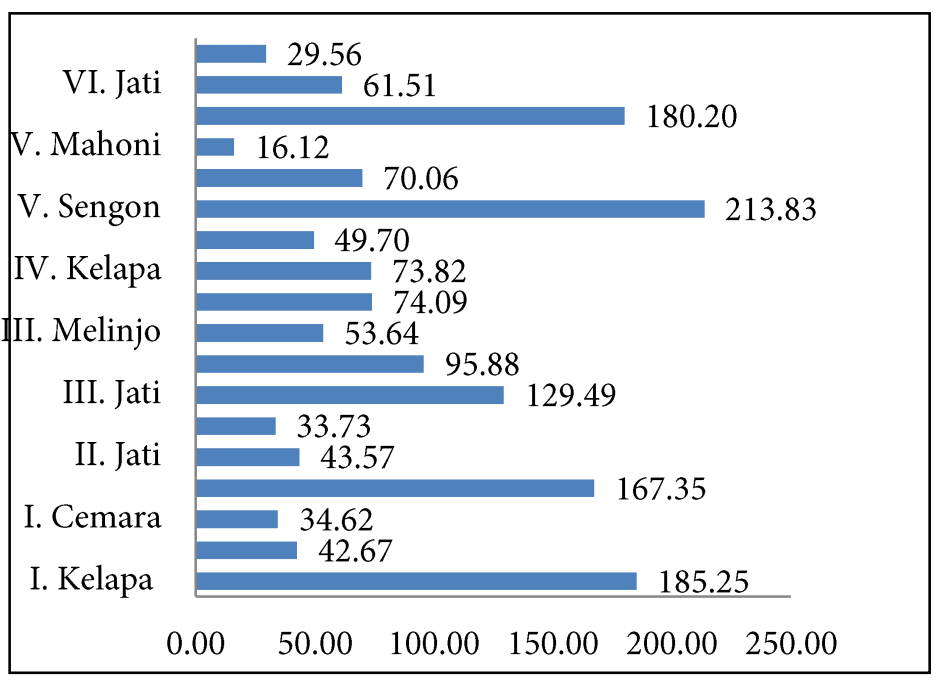

Gambar 2. Grafik Indek Nilai Penting per Blok Vegetasi

Jenis vegetasi dominan kedua setelah kelapa dan sengon adalah akasia, jati, durian dan cengkih. Tandatanda erosi di bawah tegakan tunggal yang ditunjukkan pada Gambar 3 terlihat adalah erosi percik dibawah pohon kelapa dan pohon jati. Air lolos tajuk yang terjadi lebih besar dari pada yang terjadi pada pohon sengon, cengkeh dan akasia yang berdaun kecil dan dalam tajuk yang cukup rimbun. Tanda-tanda erosi di bawah tegakan tunggal ditunjukkan pada Gambar 3.

Tanda erosi berupa gundukan tanah terjadi pada pohon kelapa yang ditanam pada batas teras, kenampakan tanah sebelah atas batang terdapat gundukan tanah yang mengumpul. Hal ini terjadi karena tanah yang terkena aliran permukaan akan terjadi proses transportasi menuju tempat yang lebih rendah kemudian terhalang oleh badan pohon. Semakin besar diameter pangkal pohon kelapa maka semakin besar halangan yang terjadi dan semakin besar gundukan tanah yang terbentuk.

Secara umum vegetasi tersebut mampu melindungi permukaan tanah yang dapat dilihat dari tanda-tanda erosi yang terjadi di bawah tegakan tunggal dengan kondisi daun, tajuk, batang yang berbeda tetapi, syarat ideal pencegahan erosi pada beberapa kondisi fisiognomi pohon tidak dapat dipenuhi. Tinggi pohon tunggal yang terlalu tinggi atau cabang pertama pohon http://jurnal.ugm.ac.id/mgi| 80 
$>7 \mathrm{~m}$ pada tanaman sengon dan jati, tajuk yang tidak begitu rapat pada pohon kelapa dan durian mengurangi efektivitas pencegahan erosi. Hal ini seperti dikatakan Utomo (1994) yang mengatakan bahwa energy kinetik hujan masih besar pada tetesan lebih dari $7 \mathrm{~m}$. Oleh karena itu untuk menyiasati permasalahan tersebut diperlukan kombinasi penanaman jenis pohon sehingga memenuhi kriteria kondisi vegetasi yang efektif pencegahan erosi dengan strata tajuk dan ketinggian pohon yang berbeda beda.

Pada bentuk daun yang relatif kecil seperti sengon, akasia dan cengkih tidak terlihat tanda erosi di bawah tegakan, tetapi pada daun jati yang cukup lebar terlihat erosi percik. Hal ini terjadi karena daun jati yang lebar justru menampung air hujan sehingga diameter hujan yang jatuh dari permukaan daun menjadi semakin besar. Hal ini sesuai dengan penelitian Budiastuti (2006) bahwa arsitektur tajuk dengan daun bulat memanjang seperti damar dan pinus dapat mengintersepsi hujan 2-5\% lebih besar dari pada daun jati yang bentuknya lebar. Tanda erosi pedestal juga terjadi di bawah seresah jati karena bentuk daunnya yang lebar sehingga melindungi tanah dari air lolos tajuk dan aliran permukaan.

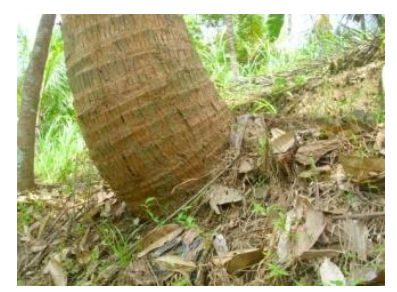

Kelapa dipinggir teras, gundukan tanah di sisi atas teras dan akar terekspos

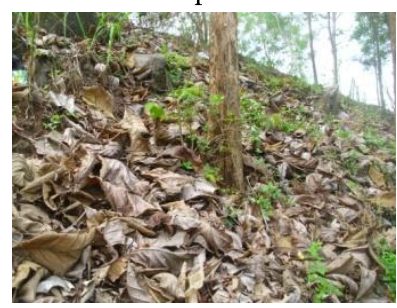

Seresah jati mudah lapuk terlihat erosi percik

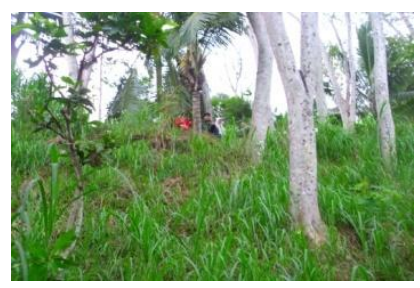

Sengon yang tinggi, tumbuhan bawah tumbuh dengan baik tanda erosi tersamar

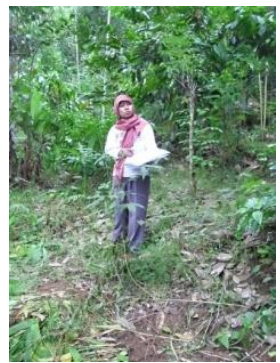

Tanda erosi alur dibawah pohon durian, terlihat seresah terbenam lumpur

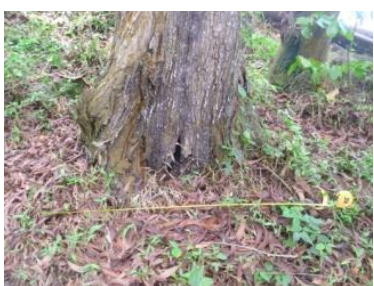

Tegakan akasia menggugurkan daun membentuk lapisan seresah tebal tidak terlihat tanda erosi

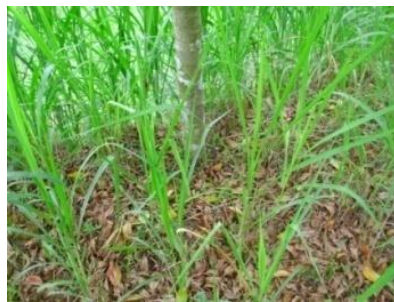

Cengkih efektif mencegah erosi karena seresah yang dihasilkan tebal. Tidak terlihat tanda erosi

\section{Gambar 3. Tanda Erosi di Bawah Tegakan Tunggal}

Untuk mengetahui hubungan vegetasi terhadap hasil proses erosi yang diamati terhadap tanda-tanda erosi yang terjadi dilakukan analisis regresi logistik antara variabel bebas dan variabel tergantung. Analisis ini dimulai dengan pengujian asumsi tidak ada multikolinearitas (no multicollinearity) untuk memastikan bahwa tidak ada korelasi antar variabel tergantung melalui uji korelasi pearson ditunjukkan pada Tabel 5. Analisis korelasi pearson menunjukkan tidak terjadi korelasi atau terbebas dari multikolinieritas apabila koefisien korelasi $\leq 0,80$ (Sugiyono dan Susanto, 2015). Hasil uji korelasi pearson pada Tabel 5 menunjukkan di antara semua variabel bebas nilai koefisien korelasi $\leq 0,80$ yang berarti tidak terdapat multikolinieritas. Semua variabel bebas dapat dianalisis dengan regresi logistik.
Setelah dilakukan uji regresi logistik berdasarkan prosedur Hosmer dan Lemeshow (2013) dengan uji akhir uji Wald terhadap variabel yang signifikan yang ditunjukkan Tabel 6 dengan nilai $p<0.05$ menunjukkan konstanta maupun koefisien variabel LBDS signifikan dan layak untuk masuk ke dalam model.

Uji akhir uji Wald pada Tabel 6 dapat dirumuskan seperti persamaan berikut:

$$
\begin{gathered}
L(x)=\ln \left(\frac{\pi_{\text {erosi }}}{1-\pi_{\text {erosi }}}\right)=3,882-7,582(\text { LBDS }) \\
\pi_{\text {erosi }}=\mathrm{P}[\mathrm{Y}=1 \mid \mathrm{x}]=\frac{1}{1+\mathrm{e}^{-3,882+7,582(\text { LBDS })}}
\end{gathered}
$$

Dari model tersebut diartikan bahwa semakin besar nilai LBDS (semakin luas bidang dasar pohon) maka peluang terjadinya erosi akan semakin kecil. Probabilitas atau Odds suatu vegetasi mengalami erosi 
setiap penambahan $1 \mathrm{~m}^{2}$ adalah sebesar 1962,55 artinya LBDS suatu vegetasi yang lebih luas $1 \mathrm{~m}^{2}$ memiliki kemungkinan terjadi erosi sebesar 1962,55 kali lebih kecil.

Hasil uji parsial uji Wald pada masing-masing variabel bebas tidak signifikan sebagai model. Variabel kerapatan tajuk tidak menunjukkan pengaruh yang signifikan karena erosi merupakan suatu proses yang panjang sehinga fluktuasi kondisi kerapatan tajuk kemungkinan berpengaruh terhadap hasil erosi visual. Pemangkasan tajuk di masa lampau yang telah tumbuh pada saat pengambilan gambar kerapatan tajuk tidak berbanding lurus terhadap erosi yang terjadi berakumulasi. Selain itu perbedaan kondisi kerapatan tajuk juga tergantung pada musim seperti jenis jati dan akasia yang banyak menggugurkan daunnya di musim kemarau.

Peluang erosi yang terjadi dengan penerapan model regresi logistik terhadap data LBDS pada semua plot pohon menghasilkan grafik seperti pada Gambar 4 . Dari grafik pada Gambar 4 dapat dilihat peluang erosi yang terjadi mendekati 0 atau tidak terjadi erosi pada nilai LBDS $1,6347 \mathrm{~m}^{2}$ pada plot vegetasi sengon Blok V dengan jumlah pohon 19 individu dengan rata-rata diameter $32 \mathrm{~cm}$. Peluang terjadi erosi paling berat 0,97 (mendekati 1) pada nilai LBDS 0,0613 dengan plot vegetasi kelapa Blok III dengan jumlah pohon 1 individu dengan diameter $28 \mathrm{~cm}$.

Tabel 5. Hasil Uji Korelasi Pearson

\begin{tabular}{|c|c|c|c|c|c|}
\hline \multicolumn{6}{|c|}{ Correlations } \\
\hline & & tinggi & $\begin{array}{c}\text { kerapatan_taj } \\
\text { uk }\end{array}$ & LBDS & $\begin{array}{c}\text { Kerapatan_po } \\
\text { hon }\end{array}$ \\
\hline \multirow[t]{3}{*}{ tinggi } & Pearson Correlation & 1 & -.097 & .237 & .099 \\
\hline & Sig. (2-tailed) & & .585 & .177 & .576 \\
\hline & $N$ & 34 & 34 & 34 & 34 \\
\hline \multirow[t]{3}{*}{ kerapatan_tajuk } & Pearson Correlation & -.097 & 1 & $.534^{\pi \pi}$ & $.621^{\pi \star}$ \\
\hline & Sig. (2-tailed) & .585 & & .001 & .000 \\
\hline & $N$ & 34 & 34 & 34 & 34 \\
\hline \multirow[t]{3}{*}{ LBDS } & Pearson Correlation & .237 & $.534^{\pi \star}$ & 1 & $.868^{\pi \pi}$ \\
\hline & Sig. (2-tailed) & .177 & .001 & & .000 \\
\hline & $N$ & 34 & 34 & 34 & 34 \\
\hline \multirow[t]{3}{*}{ Kerapatan_pohon } & Pearson Correlation & .099 & $.621^{\times \star}$ & $.868^{\star x}$ & 1 \\
\hline & Sig. (2-tailed) & .576 & .000 & .000 & \\
\hline & $N$ & 34 & 34 & 34 & 34 \\
\hline
\end{tabular}

$\star \star$. Correlation is significant at the 0.01 level (2-tailed).

Sumber: Analisis Data Primer (2014)

Tabel 6. Hasil Akhir Uji Wald terhadap Variabel Signifikan

Variables in the Equation

\begin{tabular}{|c|c|c|c|c|c|c|c|c|c|}
\hline & \multirow[b]{2}{*}{ B } & \multirow[b]{2}{*}{ S.E. } & \multirow[b]{2}{*}{ Wald } & \multirow[b]{2}{*}{ df } & \multirow[b]{2}{*}{ Sig. } & \multirow[b]{2}{*}{$\operatorname{Exp}(B)$} & \multicolumn{2}{|c|}{$95 \%$ C.I.for EXP(B) } \\
\hline & & & & & & & & Lower & Upper \\
\hline \multirow[t]{2}{*}{ Step $1^{\text {a }}$} & LBDS & -7.582 & 2.579 & 8.646 & 1 & .003 & .001 & \multirow[t]{2}{*}{.000} & \multirow[t]{2}{*}{.080} \\
\hline & Constant & 3.882 & 1.234 & 9.895 & 1 & .002 & 48.512 & & \\
\hline
\end{tabular}

a. Variable(s) entered on step 1: LBDS.

Sumber: Analisis Data Primer (2014)

Dari uraian diatas dapat dilihat bahwa sengon sesuai dengan kriteria vegetasi untuk mencegah erosi dengan syarat $L B D S \geq 1,6347 \mathrm{~m}^{2}$ per plot atau $0,4 \%$ per ha. Apabila dengan pendekatan nilai jumlah pohon maka secara ideal minimal harus ada 475 pohon sengon/ha untuk dapat mencegah erosi.

Pemanfaatan lahan Kawasan Sabuk Hijau Waduk Sermo yang dilakukan masyarakat sekitar waduk dikawatirkan memperbesar laju erosi tebing waduk. Untuk memberikan pedoman pengelolaan Kawasan Waduk Sermo dibuat Peraturan Gubernur Daerah
Istimewa Yogyakarta No. 9 Tahun 2009 yang berisi tentang larangan dan pemanfaatan yang diperbolehkan. Pelaksanaan di lapangan terdapat beberapa penyimpangan misalnya warga membudidayakan tanaman semusim (rumput gajah, pisang, ketela pohon), mencangkul untuk persiapan penanaman dan disekitar tanaman yang dibudidayakan.

Profil responden yang dapat menggambarkan kondisi Petani Sabuk HijauWaduk Sermo ditunjukkan pada Tabel 7. Petani didominasi oleh Pria 78\% dan 
Wanita 22\%. Hal ini terjadi karena kebanyakan pekerjaan yang dilakukan di sabuk hijau adalah mencari rumput yang memerlukan tenaga fisik yang kuat sehingga banyak dilakukan oleh pria dewasa. Wanita sebanyak 11 orang dari total 50 responden yang berumur maksimal 59 tahun atau umur responden pria lebih tua sampai umur 75 tahun. Jarak tempat tinggal dengan lokasi sabuk hijau juga relatif dekat, sebanyak $64 \%$ responden bertempat tinggal kurang dari $1 \mathrm{~km}$ dari waduk sermo dan 34\% antara 1-3 km. Pendidikan petani sabuk hijau bervariasi dari tidak tamat SD sampai dengan SMA, dengan dominasi pendidikan SD sebanyak 56\%. Hal ini terjadi karena pada generasi kelahiran tahun 1965-an akses transportasi untuk menuju SMP terdekat masih sulit dan berjarak $6 \mathrm{~km}$ dari Desa Hargowilis.

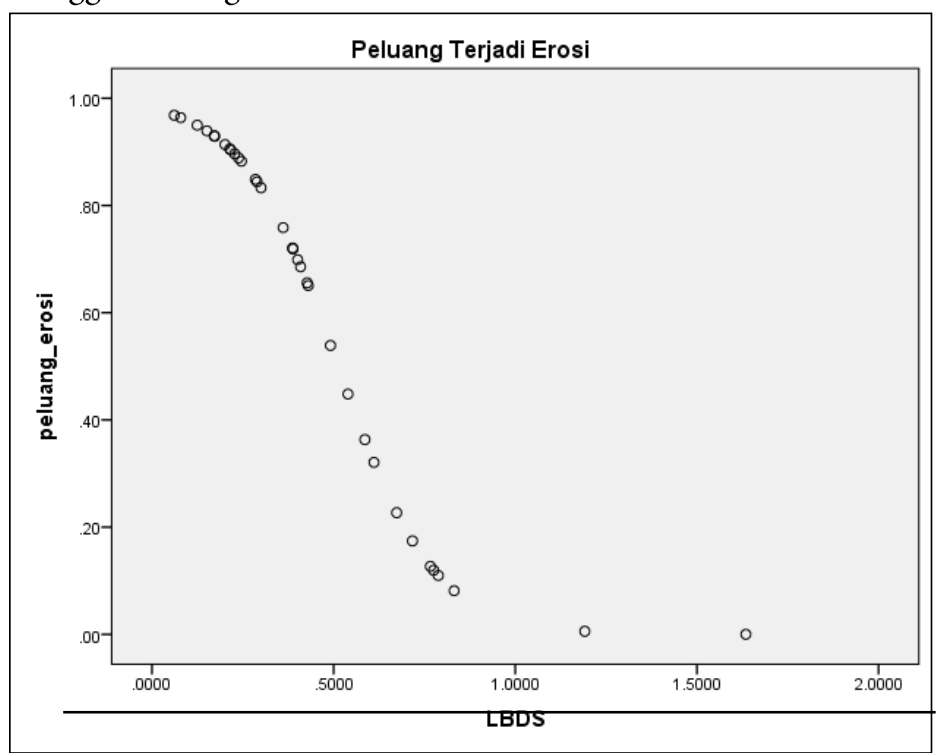

Gambar 4. Grafik Peluang Erosi berdasar Model LBDS

Sumber: Analisis Data Primer (2014)

Tabel 7. Profil Responden

\begin{tabular}{ccccccccccccccc}
\hline $\begin{array}{c}\text { Jenis } \\
\text { Kelamin }\end{array}$ & $\Sigma$ & $\%$ & $\begin{array}{c}\text { Umur } \\
\text { (Tahun) }\end{array}$ & $\Sigma$ & $\%$ & Pendidikan & $\Sigma$ & $\%$ & $\begin{array}{c}\text { Jarak } \\
\text { Rumah }\end{array}$ & $\Sigma$ & $\%$ & Status & $\Sigma$ & $\%$ \\
\hline Pria & 39 & 78 & $\leq 40$ & 3 & 6 & Tidak SD & 1 & 2 & $<1 \mathrm{~km}$ & 32 & 64 & Asli & 47 & 94 \\
Wanita & 11 & 22 & $41-56$ & 23 & 46 & SD & 28 & 56 & $1-3 \mathrm{~km}$ & 17 & 34 & Pendatang & 3 & 6 \\
& & & $\geq 57$ & 24 & 48 & SMP & 10 & 20 & $3-5 \mathrm{~km}$ & 1 & 2 & Jumlah & 50 & 100 \\
& & & & & & SMA & 11 & 22 & & & & & & \\
Jumlah & 50 & 100 & & 50 & 100 & & & & & & & & & \\
\end{tabular}

Sumber: Data Primer (2014)

Selain masyarakat (Petani FKWS), ada 2 kelompok stakeholder lain yang berkepentingan dalam kawasan Waduk Sermo yaitu BPSDA Sermo dan Pemda Kulonprogo (Dinas Pariwisata). Kepentingan dan peran dari masing masing stakeholder berbeda dalam memandang kawasan sabuk hijau yang dirangkum dalam Tabel 8. Bentuk pemanfaatan lahan sabuk hijau oleh masyarakat di dominasi oleh penanaman rumput kalanjana hampir pada semua areal di bawah tegakan. Rumput kalanjana dapat tumbuh subur di bawah tegakan kelapa dan sengon karena tajuk tanaman ini kurang rapat sehingga sinar matahari lolos tajuk yang diperlukan bagi rumput ini cukup. Daun sengon yang jatuh juga merupakan pupuk alami bagi rumput ini sehingga tidak memerlukan pupuk tambahan. Rumput kalanjana di bawah tegakan akasia kurang begitu subur karena tajuknya yang rapat sehingga syarat kebutuhan sinar matahari kurang. Hasil pemanenan rumput kalanjana oleh responden sebagai pakan ternak ratarata Rp. 90.650,00/bulan. Rata-rata petani mempunyai ternak 1 sapi dan 2 kambing. Sapi masih memerlukan pakan tambahan yang dibeli sekitar Rp. 150.000,00 per ekor/bulan. Rumput liar dan daun kleresede merupakan hasil panen yang tidak memerlukan 
pemeliharaan tanaman. Masyarakat boleh merumput diluar hak kepemilikan lahan atau di lahan orang lain. Masyarakat merumput dengan intensitas waktu setiap hari sebanyak $28 \%$ responden, $2-3$ hari sekali $16 \%$ dan pada waktu senggang $56 \%$. Nilai pemanfaatan rumput liar ini tergantung dari intensitas merumput setiap harinya atau sekitar 1 karung/hari setara Rp 5000,00. Nilai pemanfaatan rumput rata-rata responden adalah Rp. 83.800,00.

Pemanfaatan lahan sabuk hijau dalam skala kecil adalah penanaman ketela pohon, ubi kayu, talas, dan pengambilan kayu bakar. Penananam ketela pohon dilakukan sebanyak $8 \%$ responden dengan hasil $\mathrm{Rp}$. 48.000,00-Rp 204.000,00/tahun. Pengambilan kayu bakar hanya dilakukan oleh $28 \%$ responden karena mereka masih memiliki kayu bakar dari pekarangan sendiri dan menggunakan kompor gas. Besar pemanfaatan kayu bakar Rp. 100,00-Rp. $30.000,00 /$ bulan. Total nilai manfaat langsung yang dapat diperoleh keluarga petani sabuk hijau waduk sermo sebesar Rp. 190.776,00/bulan. Sebagian besar responden menganggap nilai hasil sabuk hijau terhadap penghasilan keluarga adalah besar walaupun
$42 \%$ rensponden mempunyai penghasilan antara $\mathrm{Rp}$ 1000.000,00-Rp 3000.000,00.

Kegiatan pemanfaatan sabuk hijau dapat diketahui dari pengamatan lapangan terhadap bentuk-bentuk pemanfaatan lahan. Sikap pelaku atau petani sabuk hijau akan berpengaruh terhadap kegiatan tersebut yang dapat diketahui dari penilaian sikap terhadap 3 parameter yang diajukan seperti Tabel 9. Sikap petani terhadap potensi hasil pengolahan sabuk hijau di dominasi sikap setuju menunjukkan bahwa secara langsung sabuk hijau memberikan manfaat bagi petani sabuk hijau. Peraturan Gubernur Daerah Istimewa Yogyakarta yang melarang pemanfaatan lahan untuk penanaman kalanjana dan ketela pohon tidak bisa dipatuhi . Hal ini karena kegiatan merumput bagi sebagian besar responden merupakan pekerjaan utama yang dapat dilakukan pada umurnya yang sudah tua. Berdasarkan kenyataan yang ada maka forum FKWS memberikan peraturan tidak tertulis bagi anggotanya untuk memberikan kesempatan untuk menanam kalanjana tanpa mencangkul bagi persiapan lahan di bawah jalan lingkar waduk (143 m dpl).

Tabel 8. Kepentingan Stakeholder terhadap Sabuk Hijau Waduk Sermo

\begin{tabular}{ll}
\hline \multicolumn{1}{c}{ Stakeholder } & \multicolumn{1}{c}{ Kepentingan terhadap Sabuk Hijau Waduk Sermo } \\
\hline Pemda & 1. Nilai jual keindahan untuk pariwisata yang menyumbang nilai Pendapatan Asli Daerah (PAD) \\
Kulonprogo & 2. Sumber lapangan kerja, wilayah konservasi \\
BPSDA Sermo & 1. Kelestarian untuk mencegah erosi sempadan waduk dan sedimentasi dalam mempertahankan umur pakai \\
& waduk. \\
& 2. Buffer zone yang memisahkan waduk dengan areal diluar waduk \\
Masyarakat & 1. Sumber hijauan makanan ternak dan lahan untuk menanam tanaman semusim seperti ketela dan pisang. \\
& 2. Menambah penghasilan keluarga dari hasil pemanfaatan lahan sabuk hijau \\
\hline
\end{tabular}

Sumber: Analisi Data Primer (2014)

Tabel 9. Sikap Petani terhadap Pemanfaatan Sabuk Hijau

\begin{tabular}{|c|c|c|c|c|c|c|c|}
\hline \multirow{2}{*}{ No. } & \multirow{2}{*}{ Sikap Petani Terhadap } & \multicolumn{5}{|c|}{ Interpretasi Sikap } & \multirow{2}{*}{ Jumlah } \\
\hline & & STS & TS & $\mathrm{R}$ & $\mathrm{S}$ & SS & \\
\hline 1. & Potensi Hasil Pengolahan Sabuk Hijau & 1 & 1 & 6 & 40 & 2 & 50 \\
\hline 2. & Peran Instansi Terkait & 0 & 2 & 1 & 43 & 4 & 50 \\
\hline 3. & Pengetahuan Erosi dan Sedimentasi & 0 & 0 & 2 & 40 & 8 & 50 \\
\hline
\end{tabular}

Sumber: Analisi Data Primer (2014)

Sikap terhadap potensi hasil pengolahan sabuk hijau diketahui dari sikap petani terhadap larangan menanam polowijo menunjukkan sikap ragu-ragu (R). Hal ini terjadi karena sebenarnya mereka mengetahui sosialisasi dari FKWS tetapi beberapa ruang terbuka dibawah tegakan masih memungkinkan untuk dimanfaatkan. Apabila tegakan rapat seperti pada Blok II. Akasia maka pemanfaatan lantai hutan untuk menanam ketela tidak akan tumbuh dengan baik.
Jawaban responden terhadap larangan memanen kayu yang sudah tua bervariasi dari STS - SS sehingga menunjukkan sikap ragu-ragu. Hal ini dapat dilihat bahwa sebagian kecil (2 STS, 12 TS) masih menginginkan dapat memanen kayu yang ada, walaupun dalam prakteknya tidak terjadi pemanenan kayu secara pribadi. Pohon sengon yang sudah masak tebang dengan ketinggian lebih dari $20 \mathrm{~m}$ dan tidak dimanfaatkan memberikan rasa ingin memiliki bagi 
beberapa orang. Pada kawasan hutan lindung seperti sabuk hijau waduk yang tidak memungkinkan pemanenan kayu, penanaman pohon jati terlihat kurang pas karena pada akhirnya akan menimbulkan masalah karena rawan terhadap pencurian. Peraturan inilah yang menyebabkan permudaan alami dari vegetasi kayu yang ada sulit untuk tumbuh dengan baik karena tidak adanya harapan panen. Anakan kemudian dipindah atau tidak sengaja dibersikan untuk penanaman kalanjana.

Sikap terhadap potensi hasil pengolahan sabuk hijau diketahui dari sikap petani terhadap larangan menanam polowijo menunjukkan sikap ragu-ragu (R). Hal ini terjadi karena sebenarnya mereka mengetahui sosialisasi dari FKWS tetapi beberapa ruang terbuka dibawah tegakan masih memungkinkan untuk dimanfaatkan. Apabila tegakan rapat seperti pada Blok II. Akasia maka pemanfaatan lantai hutan untuk menanam ketela tidak akan tumbuh dengan baik. Jawaban responden terhadap larangan memanen kayu yang sudah tua bervariasi dari STS - SS sehingga menunjukkan sikap ragu-ragu. Hal ini dapat dilihat bahwa sebagian kecil (2 STS, 12 TS) masih menginginkan dapat memanen kayu yang ada, walaupun dalam prakteknya tidak terjadi pemanenan kayu secara pribadi. Pohon sengon yang sudah masak tebang dengan ketinggian lebih dari $20 \mathrm{~m}$ dan tidak dimanfaatkan memberikan rasa ingin memiliki bagi beberapa orang. Pada kawasan hutan lindung seperti sabuk hijau waduk yang tidak memungkinkan pemanenan kayu, penanaman pohon jati terlihat kurang pas karena pada akhirnya akan menimbulkan masalah karena rawan terhadap pencurian. Peraturan inilah yang menyebabkan permudaan alami dari vegetasi kayu yang ada sulit untuk tumbuh dengan baik karena tidak adanya harapan panen. Anakan kemudian dipindah atau tidak sengaja dibersikan untuk penanaman kalanjana.

Sikap petani sabuk hijau terhadap peran instansi terkait menunjukkan sikap setuju. Hal ini berarti penghormatan terhadap Forum Komunikasi Waduk Sermo (FKWS), Badan Pengelola Sumber Daya Air (BPSDA) Sermo, Pemda Kulonprogo dan LSM Damar sebagai lembaga yang berhubungan dengan sabuk hijau berjalan dengan baik. Kinerja lembaga tersebut diakui karena langsung berhubungan dengan petani sabuk hijau. Peran LSM Damar yang sudah tidak ada pada saat ini masih diingat terutama pada pendampingan saat awal penanaman sabuk hijau. Sikap ragu-ragu ditunjukkan terhadap keterlibatan Pemda Kulonprogo melalui dinas pertanian ataupun kehutanan, karena lembaga ini sebenarnya tidak terlibat dalam pengelolaan sabuk hijau. Pemda Kulonprogo secara langsung hanya berkepentingan terhadap PAD dari pariwisata Sermo karena Kawasan Waduk Sermo merupakan kewenangan BPSDA DIY.

Sikap terhadap pengetahuan erosi dan sedimentasi ditunjukkan oleh semua responden sangat setuju bahwa pengolahan sabuk hijau harus sesuai dengan aturan yang berlaku. Peraturan Gubernur No. 9 tahun 2009 sebagai hukum tertulis juga berlaku bagi petani sabuk hijau. Sampai saat ini belum ada perjanjian tertulis antara BPSDA DIY sebagai pemberi hak pinjaman tanah dan petani sabuk hijau sebagai pengolah sehingga kepedulian petani sabuk hijau dalam mentaati peraturan yang ada lebih meningkat. Sosialisasi tentang pentingnya menjaga kelestarian sabuk hijau yang dilakukan FKWS dalam berbagai kesempatan telah memberikan pengetahuan tentang bahaya erosi dan sedimentasi waduk. Petani sangat setuju bahwa biaya menanggulangi permasalahan tersebut adalah besar. Pemasangan papan peringatan dilarang mencangkul juga telah dipasang pada beberapa tempat tetapi masih ditemukan petani yang mencangkul sabuk hijau dengan alasan untuk menjaga kesuburan tanah. Hal ini sesuai dengan sikap petani yang ragu-ragu terhadap kegiatan mencangkul sabuk hijau.

Petani juga bersikap ragu-ragu terhadap bahaya pengunjung wisata terhadap erosi dan sedimentasi waduk. Hal ini karena wisatawan Waduk Sermo hanya beberapa orang saja yang sampai ke areal sabuk hijau. Sebagaian besar wisatawan hanya berada di lokasi parkir dan dekat dermaga. Petani setuju bahwa dirinya ikut bertanggung jawab terhadap kelestarian sabuk hijau dan sangat setuju bahwa pemerintah ikut bertanggungjawab terhadap kelestarian sabuk hijau. Kesadaran petani berbanding terbalik dengan mulai bermunculannya warung-warung di sekitar waduk yang seharusnya dilarang didirikan dengan memotong lereng dan beberapa ada yang berada di areal sabuk hijau.

\section{KESIMPULAN}

1. Hasil penelitian menunjukkan kelapa dan sengon menjadi ciri khas vegetasi Kawasan Sabuk Hijau waduk Sermo. Vegetasi yang ada ada dalam strata pohon, tiang, sapihan, dan semai dengan indeks nilai keragaman $(\mathrm{H})$ tingkat sedang.

2. Jenis pohon yang berbeda mempunyai daya cegah terhadap erosi yang berbeda yang dapat dilihat dari kenampakan hasil proses erosi dibawah tegakan 
tunggal. Regresi logistik menunjukkan hanya variabel LBDS yang mempengaruhi kejadian erosi. Semakin besar LBDS semakin kecil peluang kejadian erosi.

3. Nilai pemanfaatan langsung hasil Kawasan Sabuk Hijau Waduk Sermo menurut petani penggarap adalah besar sehingga keterlibatan pemanfaatan areal sabuk hijau sulit untuk dicegah. PSDA DIY, Pemda Kulonprogo dan petani sabuk hijau mempunyai kepentingan yang berbeda terhadap keberadaan sabuk hijau.

\section{DAFTAR PUSTAKA}

Arikunto, S. (1998). Prosedur Penelitian Suatu Pendekatan Praktek. Bandung: Penerbit Rineka Cipta.

Azwar, S. (2013). Sikap Manusia, Teori dan Pengukurannya. Yogyakarta: Pustaka Pelajar.

Barbour, M. G., J. H Burk, dan W. D Pitts. (1987). Terrestrial Plant Ecology. New York: The Benjamin/Cummings Publishing Company, Inc.

BPT. (2009). Petunjuk Teknis Analisis Kimia Tanah, Tanaman, Air, dan Pupuk. Ed 2. Bogor: BPT.

Dibyosaputro, S., Suharko, dan D. Darmanto. (2009). Pemanfaatan Lahan Miring Kaitannya dengan
Degradasi Lahan Akibat Erosi di DAS Secang Kabupaten Kulon Progo. Yogyakarta: PSLH UGM.

Hardjowigeno, S. (1989). Ilmu Tanah. Ed 2. Jakarta: Mediyatama Sarana Perkasa.

Hosmer, D. W., dan S. Lemeshow. (2013). Apllied Logistic Regression. Ed 3. New York: John Willey and Sons, Inc.

Korhonen, L., Korhonen, K. T., Rautiainen, M. dan P. Stenberg. (2006). Estimation of Forest Canopy Cover: a Comparison of Field Measurement Techniques. Silva Fennica. 40(4), 577-588.

Morgan, R.P.C. (1980). Soil Erosion. New York: Longman Inc.

Sugiyono, dan A. Susanto. (2015). Cara Mudah Belajar SPSS dan LISREL. Teori dan Aplikasi untuk Analisis Data Penelitian. Bandung: Penerbit Alfabeta.

USDA. (2001). Rangeland Soil Quality: Water Erosion. Soil Quality Information Sheet 9. Washington.

Widjajani, B. W. (2010). Tipologi Tanaman Penahan Erosi Studi Kasus di Hutan Jati. Agrovogor III(1): 56-64.

Ziliwu, Y. (2002). Pengaruh Beberapa Macam Tanaman terhadap Aliran Permukaan dan Erosi. Tesis: Universitas Diponegoro. 